高分子骨格の 2 次非線形光学定数への影響

\author{
東京農工大学大学院工学研究科応用化学専攻 河津幸恵・渡辺敏行・戸谷健朗 \\ メキシコ大学 小川猛
}

\title{
Effects of Polymer Backbone on Second Order Nonlinear Optical Coefficients
}

\author{
Yukie Kawazu 1, Toshiyuki Watanabe ${ }^{* 1}$, Kenro Totani ${ }^{* 1}$, Takeshi Ogawa ${ }^{* 2}$ \\ ${ }^{* 1}$ Graduate School of Technology, Tokyo University of Agriculture and Technology, 2-24-16, Nakacho \\ Koganei-shi, Tokyo 184-8588, Japan \\ ${ }^{* 2}$ Instituto de Investigaciones en Materiales, Universidad Nacional Autónoma de México, Circuito Exterior, \\ Ciudad Universitaria, México DF, 04510, Mexico
}

\begin{abstract}
Polydiacethylene copolymers having different polymer backbone were synthesized consisting of same chromophore, such as dispersed red 19. Effects of polymer backbone on second-order nonlinear optical coefficients were investigated. The thin films of polydiacethylene were prepared by coating on soda-lime glass substrate and poled by corona poling at elevating temperature. The second-order NLO coefficients $d_{33}$ of the films were measured by in situ second-harmonic generation measurements and Maker fringe measurements. The $d_{33} / \mathrm{d}_{31}$ were deduced as 6.0 and 2.3 for polymer having p-cinnamate backbone and polymer having m-cinnamate at $1064 \mathrm{~nm}$ fundamental wavelength, respectively. The orientation order parameter is strongly depends on polymer backbone. To understand the temperature effects to the orientation thermal stability of polydiacethylene, the decay of second harmonic generation intensity were measured. The depoling experimental results showed that the orientation stability of p-cinnamate backbone is higher than that of m-cinnamate backbone. The order parameter and SHG decay of copolymer were also investigated.
\end{abstract}

(Received 25 December, 2003; Accepted 20 March, 2004)

\section{1. 緒 言}

非線形光学効果は光の波長, 波面, 振幅・位相を変化さ せることができ, 波長変換, 超高速光通信などへの応用が 期待されているため, 近年盛んに研究されている. 無機材 料や有機単結晶の非線形光学材料は化学式や分子式など から結晶構造を予測することができない, また大きい単結 晶を作ることが難しいなどの欠点がある.これに対し, 高 分子材料は無機材料などに比べ, 分子設計の自由度が高い, 成型加工が容易であるなどの利点のため注目を集めてい る. 非線形光学材料としての高分子は大きく分けて二種類 に分かれる. まず, 非線形光学発色団を高分子にドープし た系[1]，それから高分子の主鎖 [2]もしくは側鎖に非線形 光学発色団を化学修飾した系[3-6]である. 本研究では後 者に注目している.

二次の非線形光学効果には非中心対称構造が必要であ る. 高分子では非中心対称構造をポーリングなどの配向処 理により導入する. ポーリングによって配向させた高分子 をポールドポリマー[1]という.

ポールドポリマーとしてはビニルポリマーが最初に用
いられていたが,これは緩和しやすいという久点があった ため, 緩和を防ぐための方法が考えられるようになった. 緩和を防ぐ方法としてはポリイミドなどのガラス転移温 度の高いポリマーを用いる方法 [5], 非線形発色団を架橋 させる方法 $[7]$ などがとられた. 本研究では架橋が可能な 高分子に注目した.

架橋型ポリマーはポーリングにより配向した状態で架 橋することができるのでポーリング後の配向緩和を防ぐ ことができる. そこで本研究ではジアセチレン基を架橋部 位として持つ高分子 $[3,4]$ について研究を行った．主鎖骨 格に $p$-cinnamate を持つものと, $m$-cinnamate を持つもの, そして $p$-cinnamate と $m-c$ innamate の共重合体のポリマー を用いて, ポリマーの主鎖骨格による非線形光学定数への 影響について検討した。

\section{2. 実 験}

\section{1 フィルムの作製}

本研究で使用した試料は非線形光学発色団として Dispersed Red 19 を側鎖にもつ poly（hexa-2, 4- 
diynylene-1,6-dioxydicinnamates)である. 化学構造を 1 に示 す.

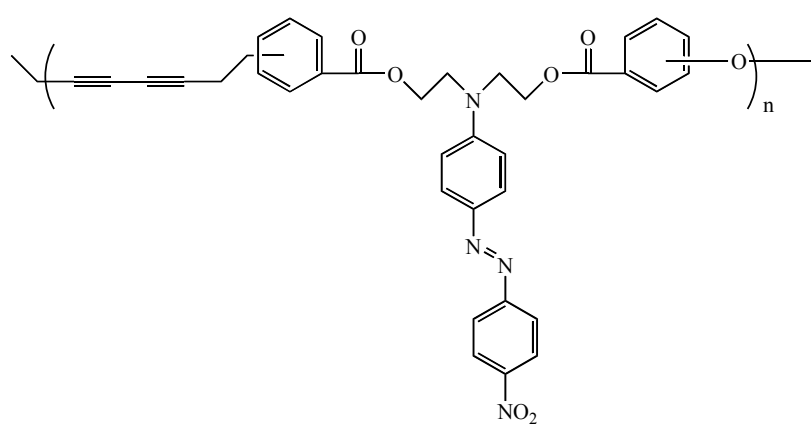

1

試料を N, N-ジメチルホルムアミド(DMF)（試薬特級，国 産化学(株))または 1-メチル-2-ピロリドン(東京化成工業 (株))に溶かし溶液を作成した。濃度は $10 \mathrm{wt} \%$ した。ガ ラス基板（厚さ 0.8-1.0 mm, MATSUNAMI）は中性洗剤, 水 道水, 蒸留水, 2-プロパノール(試薬特級, 国産化学(株)), メタノール(電子工業用, 純正化学(株))で超音波洗浄した (各 15 分以上).これらの溶液を洗浄したガラス基板にス ピンコート法により膜を作成し, $90^{\circ} \mathrm{C}$ で真空乾燥した. ス ピンコート時の回転数は $2000 \mathrm{rpm}$, 製膜温度は $80^{\circ} \mathrm{C}$ であっ た. 膜厚は触針式膜厚計（DEKTAK IIA，SLOAN)により測定し た.

\section{2 分極処理}

ガラス基板の裏に電極としてアルミニウムを蒸着 （JEE-400, JEOL）し，アルミ箔を導電性ペーストで接着 し，基板を作成した．ポーリングは図 1 のように, $1064 \mathrm{~nm}$ のレーザー光（Nd:YAG レーザー, $8 \mathrm{~ns}, 10 \mathrm{~Hz}$ )（Surelite I, Cont inuum) を入射した時の光第二高調波(SH) 強度を 測定しながらコロナポーリングを行った.

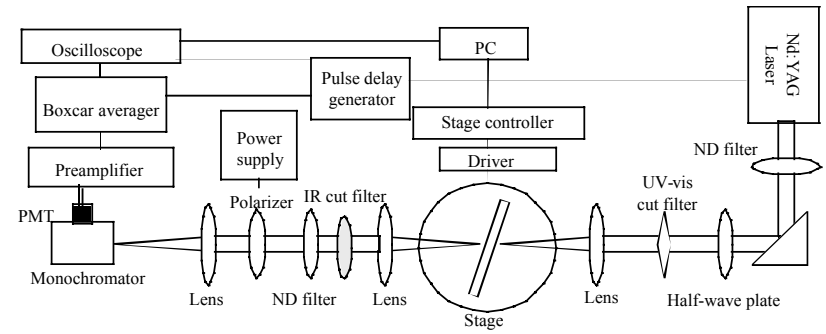

Fig. 1 Schematic diagram of SHG measurement system.

針状の電極を用い, 電極間距離を $1 \mathrm{~cm}$ とした. ポーリン グの電界は高電圧装置(PHS 10K-10, 菊水電子工業(株))を 用いて $4 \mathrm{kV}$ をかけた。 温度はスライダックで調整し SH 強 度が最大になった温度で SH 強度が一定となるまでの間保 持した.このあと, 電圧をかけたまま室温まで急冷したあ と電圧を除去した.

\section{3 線形および非線形光学特性の評価}

非線形光学定数を求めるために必要な屈折率を測定し た。フィルムの屈折率をプリズムカッップリング法
(PC2010, Metricon)により測定した. 用いたレーザーの波 長は $532 \mathrm{~nm}, 632.8 \mathrm{~nm}, 780 \mathrm{~nm}$ である. 測定は TE モード で行った, ポーリング後蒸着した Al をはがし, メーカー フリンジ法により非線形光学定数の測定を試みた. 基本波 としては Nd:YAG レーザー（8 ns, $10 \mathrm{~Hz}$ ) (Surelite I, Continuum）を用いた。一般的にポールドポリマーの非線 形光学定数は $d_{33}$ と $d_{31}$ で表すことができる. $\mathrm{s}$ 偏光を試 料に入射すると, Y 方向に振動する電界を照射することが できる. 試料から放出される SHG の p 偏光を測定すること により，X およびZ方向に振動する SHG の成分のみ測定で きる. よって, 測定される SHG は $d_{3}$ に比例する. $\mathrm{p}$ 偏 光を試料に入射すると, X 成分と Z 成分をもつ光を物質に 照射することになり, 分子にはX 方向に振動するフォトン と Z 方向に振動するフォトンが照射されるので, 同様に $p$ 偏光の SHG を検出すれば, $d_{33}$ と $d_{31}$ のふたつの成分の 和からなる SHG 強度を測定することになる．これらふたつ の測定を利用することにより， $d_{31}$ と $d_{33}$ が求められる. 本実験では入射光を $\mathrm{s}$ 偏光, 出射光を $\mathrm{p}$ 偏光としたとき $(\mathrm{s}-\mathrm{p})$, 入射光を $\mathrm{p}$ 偏光, 出射光を $\mathrm{p}$ 偏光としたとき $(\mathrm{p}-\mathrm{p})$, それぞれ- $60^{\circ}$ から $60^{\circ}$ まで測定を行った. リファレンス には $\mathrm{Y}$-cut 水晶 $\left(d_{11}=0.4 \mathrm{pm} / \mathrm{V}\right)$ を用いた.

2. 4 オーダーパラメーターの測定

$d_{33}$ と $d_{31}$ の比, あるいはポーリング前後の紫外-可視吸収 スペクトルの吸光度測定 (V-560, JASC0) (走查速度 200 $\mathrm{nm} / \mathrm{min}$, バンド幅 $2.0 \mathrm{~nm}$ ) からオーダーパラメーターを求 めた. 紫外可視吸収スペクトルではオーダーパラメーター $S$ を以下の式により求めることができる.

$S=1-\frac{A_{\perp}}{A_{0}}$

ここで, $A_{0}$ はポーリング前の吸光度, $A_{\perp}$ はポーリング 後の吸光度である.

\section{3. 結果と考察}

温度上昇に伴う, 発色団の配向により, SH 強度は上がっ ていくが, ある時点（ガラス転移温度付近）で SH 強度が 下がっていく.P体 40\%, m 体 60\%の cinnamate copolymer の例を図 2 に示す. 他の試料でも同様の傾向が見られる. これは $\mathrm{Tg}$ 付近でイオン導電性が発現し, コロナポーリン グによる電界が減少することに起因する. SH 強度が減少し 始める直前の温度で保持し, ポーリングを行った. この温 度で SH 強度が一定となるまで電圧を印加し, 室温まで急 冷してから電圧を除去した。

屈折率は紫外-可視吸収スペクトル測定の結果をクロー マス・クロニッヒ変換し, プリズムカップリング法で求め られた屈折率とフィッティングすることにより求めた.こ れらのポリマーは発色団の化学構造打よび導入率がほぼ 同じであるため, 全てのポリマーの屈折率が同じであると 仮定した. 波長 $1064 \mathrm{~nm}$ での屈折率は 1.63，532 nm では 1.85 となった. この屈折率を使い, メーカーフリンジ法に 
より非線形光学定数を求めた.

SH 強度と $d$ 定数の関係は次式で表される $[8]$.

$$
P_{2 \omega}=\left(\frac{512 \pi^{3}}{A}\right) d^{2} t_{g}^{4} t_{\omega}^{4} T_{2 \omega} P_{\omega}^{2}\left(\frac{1}{\left(n_{\omega}^{2}-n_{2 \omega}^{2}\right)^{2}}\right) \sin ^{2} \Psi
$$

ここで, $P_{2 \omega}$ は $\mathrm{SH}$ 強度， $P_{\omega}$ は入射光強度， $n_{\omega}$ および $n_{2 \omega}$ は それぞれ，基本波抢よび高調波に打ける屈折率，Aはレー ザー光の照射面積, $d$ は非線形光学定数, $t_{\omega}$ および $T_{2 \omega}$ は 基本波抢よび高調波に扎けるフレネルの透過因子， $t_{\mathrm{g}}$ は基 本波に対する基板の透過因子を表している.

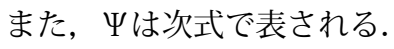

$$
\psi=(2 \pi L / \lambda)\left(n_{\omega} \cos \theta_{\omega}-n_{2 \omega} \cos \theta_{2 \omega}\right)
$$

ここで，Lはフィルムの厚さ，入は入射光の波長を表し ている. $\theta_{\omega}$ および $\theta_{2 \omega}$ は基本波および高調波に対する屈 折角である. 試料の SH 強度を参照物質 ( $\mathrm{Y}$-cut 水晶) のSH 強度と比較することにより, ポールドポリマーの非線形光 学定数が得られる. 表 1 に得られた非線形光学定数の值を 示す.

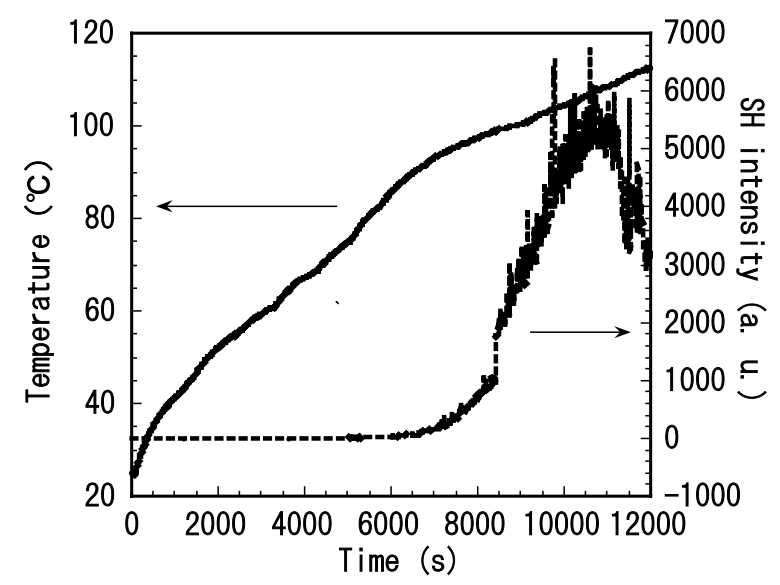

Fig. 2 SHG intensity and sample temperature as a function of poling time.

ポールドポリマーの測定において入射光を $\mathrm{p}$ 偏光, 検出を $\mathrm{p}$ 偏光としたとき $(\mathrm{p}-\mathrm{p})$ に求められる非線形光学定数 $d$ は 以下の式になる $[5]$. $d=\left(d_{33} \sin ^{2} \theta_{\omega}+d_{31} \cos ^{2} \theta_{\omega}\right) \sin \theta_{2 \omega}$

$+2 d_{31} \cos \theta_{\omega} \sin \theta_{\omega} \cos \theta_{2 \omega}$

入射光を $\mathrm{s}$ 偏光, 検出を $\mathrm{p}$ 偏光としたとき $(\mathrm{s}-\mathrm{p})$ に求めら れる非線形光学定数 $d$ は以下の式になる.

Table 1. Nonlinear optical coefficients and order parameter of poled polymer having cinnamate backbone.

\begin{tabular}{lccrc}
\hline Sample & $d_{33} / \mathrm{pmV}^{-1}$ & $d_{31} / \mathrm{pmV}^{-1}$ & $d_{33} / d_{31}$ & Order parameter \\
\hline$(1)$ & 72 & 12 & 6.0 & 0.54 \\
$(2)$ & 60 & 15 & 4.0 & 0.30 \\
$(3)$ & 96 & 23 & 4.2 & 0.34 \\
$(4)$ & 56 & 16 & 3.5 & 0.18 \\
$(5)$ & 60 & 20 & 3.0 & ---- \\
$(6)$ & 12 & 5 & 2.3 & ----- \\
\hline
\end{tabular}

(1) p-cinnamate $100 \mathrm{~mol} \%$, (2) p-cinnamate $80 \mathrm{~mol} \%$, m-cinnamate $20 \mathrm{~mol} \%$, (3) p-cinnamate $60 \mathrm{~mol} \%$, m-cinnamate $40 \mathrm{~mol} \%$, (4) p-cinnamate $40 \mathrm{~mol} \%$, m-cinnamate $60 \mathrm{~mol} \%$, (5) p-cinnamate $20 \mathrm{~mol} \%$, p-cinnamate $80 \mathrm{~mol} \%$, (6) m-cinnamate $100 \mathrm{~mol} \%$

$d=d_{31} \sin \theta_{2 \omega}$

表 1 の值は, フィルム自体による SH 光の吸収を考慮して いない，それゆえ，厚みのあるフィルムでは非線形光学定 数が大きいにもかかわらず, 見かけの值は小さくなる. し たがって， $d_{33}$ および $d_{31}$ の絶対值からは, パラ体とメタ体 の割合による傾向は現れなかったが.これに対して $d_{33}$ と $d_{31}$ の比には, 吸収補正による影響は現れないので, $d_{33}$ と $d_{31}$ の比はパラ体の割合が大きいポリマーほど大きく,メタ 体の割合が大きいポリマーほど小さくなった. この実験結 果は, パラ体の割合が大きいほど, 側鎖に導入された非線 形発色団か配向しやすいということを意味している. ポー ルドポリマーの場合 $d_{33}$ および $d_{31}$ は以下の式で表すことが できる[1].

$d_{33}=\beta_{z z z}\left\langle\cos ^{3} \theta\right\rangle \cdot N f_{\omega}^{2} f_{2 \omega}$

$d_{31}=\frac{1}{2} \beta_{z z z}\left(\langle\cos \theta\rangle-\left\langle\cos ^{3} \theta\right\rangle\right) \cdot N f_{\omega}^{2} f_{2 \omega}$

ここで, $\frac{\mu E}{k T}\left\langle\left\langle 1\right.\right.$ の場合, $\langle\cos \theta\rangle,\left\langle\cos ^{2} \theta\right\rangle$ おび

$\left\langle\cos ^{3} \theta\right\rangle$ は以下のように近似できる [1]. 
メタ体が多いポリマーの緩和時間が短いのはガラス転移 温度との関係だと思われる.表 2 のようにメタ体の割合が 多くなるほどポリマーのガラス転移温度は低くなる.この ため, 測定温度であった $80^{\circ} \mathrm{C}$ ではメタ体のガラス転移温度 に近くなり, 緩和が速く起きている.一方, 室温ではほと んど緩和は観測されなかった。

\section{4. 結 論}

側鎖型高分子非線形光学材料の非線形光学定数に対する 主鎖骨格の影響について検討した，その結果，主鎖骨格中 に含まれる p-cinnamate 基の割合が多いほど, 分極処理後 のオーダーパラメーターが増加し, さらには分極処理後の SHG 強度の経時変化も小さいことがわかった.これらの実 験事実は, 非線形光学材料を設計する際に, 非線形光学発 色団のみならず，主鎖骨格の構造も考慮しなければならな いことを示している.

\section{参考文献}

1. K. D. Singer, J. E. Sohn and J. Lalama, Appl. Phys. Lett., 49 , 248(1986).

2. C. Ye, T. J. Marks, J. Yang and G. K. Wong, Macromolecules, 22, 722 (1987) .

3. H. Miura and T. Ogawa, Polym. Bulletin 49 , 103(2002).

4. S. Hernandez, T. Ogawa, T. Watanabe, and S. Miyata, Mol. Cryst. Liq. Cryst., 374, 503 (2002).

5. 5. J. W. Wu, J. F. Valley, S. Ermer, E. S. Binkley, J. T. Kenney, G. F. Lipscomb and R. Lytel, Appl. Phys. Lett., 58 , 255(1991).

6. L. R. Dalton, A. W. Happer, B. H. Robinson, Proc. Natl. Acad. Sci. USA, 94, 4842 (1997).

7. I. Teraoka, D. Jungbauer, B. Reck, D. Y. Yoon, R. Twieg, C. G. Willson, J. Appl. Phys., 69 , 2568(1991) .

8. J. Jerphagnon and S. K. Kurtz, J. Appl. Phys., 41 , 1667(1970) . 